\title{
Microsatellite-associated heterosis in hatchery-propagated stocks of the shrimp Penaeus stylirostris
}

\author{
Nicolas Bierne $^{\mathrm{a}, \mathrm{b}^{, *}}$, Ivan Beuzart ${ }^{\mathrm{a}}$, Vincent Vonau ${ }^{\mathrm{a}}$, François Bonhomme ${ }^{\mathrm{b}}$, Edouard Bédier and \\ AQUACOP ${ }^{a}$ \\ a'Laboratoire d'Aquaculture Tropicale, IFREMER, Centre Océanologique du Pacifique BP 7004, Taravao, Tahiti, \\ French Polynesia \\ bLaboratoire Génome, Populations, Interactions, CNRS UPR 9060, Université Montpellier II, F-34095 Montpellier, \\ France \\ *: Corresponding author : Laboratoire Génome, Populations, Interactions, Station Méditerranéenne de \\ I'Environnement Littoral, 1 Quai de la Daurade, 34200 Sète, France. Tel.: +33-4-67-46-33-88; fax: +33-4-67-46- \\ 33-99; email: n-bierne@univ-montp2.fr
}

\begin{abstract}
Correlation between DNA microsatellite heterozygosity and growth rate was investigated in two hatchery-propagated stocks of the shrimp Penaeus stylirostris, which had been genetically isolated from wild founders for 17 generations, and from each other for five more generations. Presumed demographic history of these populations suggested that they were maintained at small effective population sizes, and this was confirmed by significant changes in allelic frequencies between the two stocks. Despite a small sample size $(n=60)$ and a small number of loci screened, a significant positive correlation was detected between microsatellite tri-locus heterozygosity and growth rate in one of the two stocks $(r=0.3, P=0.02)$. In the other stock $(n=48)$, the positive correlation was not significant, but the combined test of single locus heterozygote advantage over the three loci was significant $(P=0.005)$.

Use of DNA microsatellite markers, whose selectively neutral status is generally accepted, allowed us to reject the hypothesis of direct overdominance at marker loci as an explanation for an association of growth rate with heterozygosity. The average depression associated with one locus in our case is above or equivalent to the amount observed for a 10\% increase of inbreeding in other species. These results suggest that heterozygosity at neutral marker loci is sufficiently well correlated with individual inbreeding coefficients to reveal a significant residual inbreeding load for growth rate in Tahitian $P$. stylirostris stocks. Inbreeding during hatchery propagation was, thus, insufficient to purge the ancestral load.
\end{abstract}

Keywords: Microsatellites; Inbreeding depression; Marker-associated heterosis; Heterozygosity; Penaeus stylirostris 


\section{Introduction}

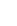

Although the world penaeid shrimp culture industry largely still relies on wild broodstock (Pullin et al., 1998), an industry completely based on hatchery-propagated stocks has been developed in several places, such as the French Pacific overseas territories (French Polynesia and New Caledonia). The achievement of control of maturation and spawning by IFREMER in the late 1970s (AQUACOP, 1979) led to the development of closed populations imported for commercial production. Since an IHHNV (infectious hypodermal and hematopoietic necrosis virus) resistant strain of Penaeus stylirostris (SPR 43 strain, Weppe et al., 1992) was obtained in 1989, it has become the main cultivated strain in these territories. The

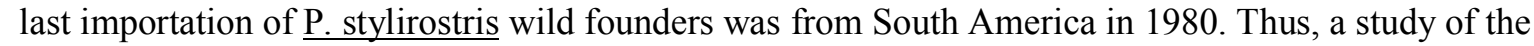
genetic variability after more than 15 years (22 generations) of culture was considered essential.

Founder effect and genetic drift decrease the ancestral genetic variability of small populations, variability which is supposed to be essential for the initiation of domestication (Sunden and Davis, 1991). However, an increase in inbreeding giving rise to inbreeding depression may lead to poorer performance and even to population extinction. A slow increase of inbreeding, though, could purge the genetic load, as experimentally demonstrated in Drosophila melanogaster by Latter et al. (1995), without losing considerable useful genetic variability, when favorable alleles are already at high frequency in wild populations.

Genetic marker-assisted study of penaeid species has been hampered by extremely low levels of allozyme variation (Mulley and Latter, 1980 ; Hedgecock et al., 1982 ; Laubier et al., 1984 ; Sbordoni et al., 1987). The development of new highly-variable DNA markers makes it possible to overcome this difficulty (Garcia et al., 1994 ; Bagshaw and Buckholt, 1994 ; Wolfus et al., 1997). Microsatellites appear to be appropriate markers to observe residual variability in long-cultured stocks such as those in Tahiti.

$$
\text { Correlations between allozyme multilocus heterozygosity (MLH, number of heterozygous loci per }
$$
individual) and fitness-related traits such as growth, viability or physiological parameters have been under study for decades. Positive correlations have been reported for various organisms, especially marine 
1 bivalves (Zouros, 1987), salmonid fishes (Leary et al., 1984) and pine trees (Bush et al., 1987) (see Mitton

2 and Grant, 1984 and David, 1998 for reviews, and Britten, 1996 for a meta-analysis). In penaeids,

3 however, allozyme polymorphism is so low that very large samples would be required to have a sufficient

4 representation of the fitness trait variance in each MLH class, especially in the high multilocus

5 heterozygous classes. No such study on penaeids can be found in the literature, a lack of knowledge which

6 could be filled by the use of microsatellites.

7 Population genetic models have been developed (review in David, 1998) explaining (i) the gene

8 heterozygosity - fitness correlation (Turelli and Ginzburg, 1983 ; Smouse, 1986 ; Mitton, 1993 ; Deng and

$9 \mathrm{Fu}, 1998$ ) and (ii) neutral marker heterozygosity - fitness correlation due to association with selected genes (deleterious or overdominant) in small populations (Ohta and Kimura, 1970, 1971 ; Ohta, 1971, 1973 ; Zouros, 1993) or in populations with partial inbreeding (Ohta and Cockerham, 1974 ; Strobeck, 1979 ; Charlesworth, 1991 ; Zouros, 1993). Nevertheless, as the neutral status of allozymes is questionable, the debate was at first concentrated on the comparison of two hypotheses : the "direct overdominance " hypothesis that treats allozymes as the causative agent of the correlation versus the “associative overdominance " hypothesis (Ohta, 1971 ; Zouros et al., 1980) where neutral markers are indicators of genetic conditions responsible for the correlation. More recently, David et al. (1995) proposed a further partition of the " associative overdominance " hypothesis into the " local effect" hypothesis where markers reflect variation at fitness loci localized in their chromosomal vicinity and the " general effect" hypothesis where homozygosity at marker loci correlates with overall genomic homozygosity in partly inbred populations (also see David, 1998). However, bottlenecks enhance linkage disequilibrium as well as inbreeding, and the partition of associative overdominance into local and general effects is presently not well understood (Zouros, 1993).

The development of a new class of genetic marker loci exhibiting variation in non-coding DNA sequences, and which are most unlikely to be anything other than selectively neutral, allows a new approach to this problem, as only " associative overdominance " can apply in this case (Zouros and Pogson, 1994 ; Bierne et al., 1998 ; Pogson and Fevolden, 1998). Pogson and Zouros (1994) found in the 
1

scallop Placopecten magellanicus, a MLH - growth correlation with seven allozyme loci, while a set of eight nuclear DNA loci (restriction fragment-length polymorphisms, RFLPs) failed to produce a significant correlation. A second test of the associative overdominance hypothesis using DNA markers was published by Pogson and Fevolden (1998), showing a positive correlation between growth rate and RFLP marker heterozygosity at ten loci within a single population of Atlantic cod, Gadus morhua.

Use of the three microsatellite loci recently developed in the shrimp Penaeus stylirostris (Vonau et al., 1999), and a heterologous locus from $\underline{P}$. vannamei (Garcia et al., 1996), allowed us to study the MLH/growth correlation at presumably neutral genetic markers, within closed populations that had been maintained at small effective sizes for 22 or 24 generations. We explore the possibility of using markerassociated heterosis to evaluate, with Ohta's $(1971,1973)$ formula, the residual inbreeding load in such inbred populations with unknown pedigrees.

\section{Materials and methods}

\subsection{History of the populations studied}

The last import of $\underline{P}$. stylirostris wild founders from Mexico to two IFREMER experimental hatcheries, located in Tahiti (COP) and in New Caledonia (SASV), took place in 1980. The exact number of founders is, unfortunately, unknown. As the shrimp industry developed more quickly in New Caledonia, SASV used more breeders $(\mathrm{N} \approx 100)$ at each reproduction than the COP experimental hatchery $(\mathrm{N} \approx 20)$. However, it cannot be ruled out that these populations went through stronger genetic bottlenecks than these optimistic values might suggest. In 1988, the COP stock became extinct, and was reinitiated following the import of a part of the SASV production at the post-larvae stage. Since 1989, no transfer of breeders has been made between the two hatcheries. A genetic improvement program began at the COP facilities in 1992. We used one stock from this program, where the number of breeders selected was 24 (16 males and 
18 females) at each generation. This led to an effective population number $\mathrm{N}_{\mathrm{e}}=\left(4 \mathrm{~N}_{\mathrm{m}} \mathrm{N}_{\mathrm{f}}\right) /\left(\mathrm{N}_{\mathrm{m}}+\mathrm{N}_{\mathrm{f}}\right)=21.33$,

2 where $\mathrm{N}_{\mathrm{m}}$ is the number of males and $\mathrm{N}_{\mathrm{f}}$ the number of females. In Tahiti, a second hatchery (Ecloserie

3 Polyvalente Territoriale, EPT) was constructed in the late 1980s. This hatchery depended on the COP

4 breeders until 1993, when it started to use its own breeders only. The presumed demographic histories of

5 the COP and EPT populations are summarized in Figure 1.

7

8

9

A first sampling of 30 individuals from the EPT population was made without phenotypic characterization (EPT-g) in late 1996 (Vonau et al., 1999). A second sampling, including sex determination and weighing of 48 individuals, was done two generations later, in late 1997 (EPT-g 2 . Two further samplings, each of 30 individuals, were made at two different times in early 1997 in the same COP population $\left(\mathrm{t}_{1}:\right.$ mean weight $=26.8 \mathrm{~g}, \mathrm{t}_{2}:$ mean weight $\left.=43.1 \mathrm{~g}\right)$. Each individual was sexed, weighed and sampled for hemolymph. The hemolymph was diluted in an anticoagulant, Alsever solution pH 7 (30 mM trisodium citrate, $115 \mathrm{mM}$ glucose, $338 \mathrm{mM} \mathrm{NaCl}, 10 \mathrm{mM}$ EDTA) for DNA extraction. All animals sampled at the same time belonged to the same cohort, and thus had the same age.

\subsection{DNA extraction, Polymerase Chain Reaction (PCR) procedures and electrophoresis}

The fast Chelex extraction method (modified from Singer-Sam et al., 1989) was used. Hemolymph samples (corresponding to one million cells) were centrifuged at $6,000 \mathrm{~g}$ for $2 \mathrm{~min}$. The supernatant was saved and $500 \mu \mathrm{l}$ of $5 \%$ chelating resin (Chelex, Biorad, Richmond, VA USA) and $5 \mu$ l of proteinase K $(10 \mathrm{mg} / \mathrm{ml})$ were added to each sample tube. The mixtures were shaken and heated for $4 \mathrm{~h}$ in an incubator at $55^{\circ} \mathrm{C}$, then vortexed, heated again at $100^{\circ} \mathrm{C}$ for $15 \mathrm{~min}$, vortexed a second time and centrifuged at $10,000 \mathrm{~g}$ for $2 \mathrm{~min}$. The supernatant was stored at $-20^{\circ} \mathrm{C}$ until it was used as template for PCR. 


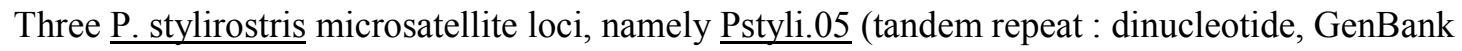
accession number : AF097487), Pstyli.19 (tandem repeat : mono and dinucleotide, GenBank accession number : AF097488) and Pstyli.09 (tandem repeat : dinucleotide, GenBank accession number :

AF097489) (full details are given in Vonau et al., 1999) and a heterologous locus from $\underline{P \text {. vannamei, }}$ called Vanna.02, were used. Vanna.02 primers were designed from the published sequence of a microsatellite (Garcia et al., 1996) in two flanking open reading frames which are thought to be highly conserved across taxa : Primer 1 =5'-GGATAACACTGATTAGATATCACGG-3' and Primer $2=5$ 'TAAATGTACACGAGATGCACC-3'. This marker was screened only in the EPT samples.

All other heterologous microsatellite loci which were tried, from P. monodon (Brooker at al., in press) and $\underline{\mathrm{P} . \text { japonicus }}$ (Moore et al., 1999), and for which primers were designed a priori in non-coding sequence, failed to amplify. This is in accordance with results of Moore et al. (1999), and with two mtDNA analyses (Palumbi and Benzie, 1991 ; Baldwin et al., 1998) which revealed that morphological similarity in penaeids masks very large genetic differences.

Twelve $\mu 1$ of PCR mixture, containing $0.5 \mu \mathrm{M}$ of each primer, $2 \mathrm{mM} \mathrm{MgCl}_{2}, 0.2 \mathrm{mM}$ of each dNTP and 0.25 unit of red Goldstar DNA polymerase (Eurogentec, Liège, Belgium), was added to $3 \mu 1$ of DNA solution during the first 2 min- $94^{\circ} \mathrm{C}$ denaturing stage of the PCR program (Hot Start). Thirty PCR cycles (30 sec at $94^{\circ} \mathrm{C}, 1 \mathrm{~min}$ at the optimum hybridization temperature, $1 \mathrm{~min}$ at $72^{\circ} \mathrm{C}$ ) were run in a PTC 100 programmable thermal controller (MJ Research, Waltham, MA, USA). PCR products were electrophoresed through 6\% polyacrylamide gels (acrylamide: bisacrylamide, 29:1, $7 \mathrm{M}$ urea) using $0.5 \mathrm{X}$ Tris-Borate-EDTA buffer. The gels then were silver-stained according to Bassam et al. (1991).

\subsection{Genetic diversity analyses}

Allele frequencies, observed and unbiased expected heterozygosities (Nei, 1978), and Weir and Cockerham (1984) estimation of Wright's (1951) F-statistics ( $\mathrm{F}_{\text {is }}$, which measures within-population departures from Hardy-Weinberg equilibrium (HWE), and $\mathrm{F}_{\mathrm{st}}$, which quantifies genetic differentiation 
between pairs of populations) were computed using the Genetix 3.3 software (Belkhir et al., 1996-1999).

Departure of $\mathrm{F}_{\text {is }}$ and $\mathrm{F}_{\text {st }}$ from zero was tested using the permutation approach provided by this software. Where more than one test was performed, the probability threshold level was adjusted according to the Bonferroni procedure.

\subsection{Variance of allelic frequencies}

Estimates of variance of allele frequencies were made according to the theory of selectively neutral alleles in finite populations (Waples, 1989). Estimates of temporal variance of allelic frequencies, $\mathrm{F}_{\mathrm{c}}(\mathrm{Nei}$ and Tajima, 1981), were computed for each pair of samples and compared to expectations under the presumed demographic parameters. When applicable (the same population at two different times), pergeneration effective population sizes, $\mathrm{N}_{\mathrm{e}}$, also were estimated.

\subsection{Linkage disequilibrium}

Weir's (1979) two-locus correlation coefficient, $\mathrm{R}^{2}$, was estimated using the Black and Krafsur (1986) method and its departure from zero was tested using a permutation approach provided by the procedure LINKDIS in Genetix. The expected correlation corresponding to the effective sizes estimated for the various presumed demographic histories and the assumption of no physical linkage between loci were calculated using Weir and Hill's (1980) formula :

$$
E\left(R^{2}\right)=\frac{(1-c)^{2}+c^{2}}{2 N_{e} c(2-c)}+\frac{1}{n}+\frac{1}{2 N_{e} c(2-c)}
$$

where $\mathrm{c}$ is the recombination rate between the two loci (here, we assumed they were unlinked and used 
presumed real population sizes over the 22 or 24 generations). The last term in the equation is a correction for monogamy. The haploid chromosome number in P. stylirostris is 46 (Nakaura et al., 1988), so the probability of a physical linkage between a pair out of three microsatellites picked up at random is small.

\subsection{MLH/growth correlation}

Since no difference in weight was detected between males and females $(F=0.22, \mathrm{df}=29, \underline{\mathrm{P}}=0.64$ for COP- $\mathrm{t}_{1} ; \mathrm{F}=2.13, \mathrm{df}=29, \underline{\mathrm{P}}=0.155$ for $\mathrm{COP}-\mathrm{t}_{2} ; \mathrm{F}=0.17 ; \mathrm{df}=47 ; \underline{\mathrm{P}}=0.68$ for $\left.\mathrm{EPT}-\mathrm{g}_{2}\right)$, the data for sexes were pooled. To facilitate comparisons among samples and to obtain a normally distributed variable, individual weight was $\log _{\mathrm{e}}$-transformed and expressed in standard deviation units from the sample mean (standardized deviates). The locus-specific effects of heterozygosity on growth were expressed as:

$$
\underline{\mathrm{d}}=\underline{\mathrm{M}_{\mathrm{SHet}}}-\underline{\mathrm{M}_{\mathrm{SHom}}}
$$

$\underline{\mathrm{M}}_{\mathrm{SHet}}$ and $\underline{\mathrm{M}}_{\mathrm{SHom}}$ being the mean standardized growth in heterozygotes and homozygotes, respectively (Gaffney, 1990; Bierne et al., 1998). A homozygote depression for growth was calculated using the formula:

$$
\delta=1-\underline{\mathrm{W}}_{\mathrm{Hom}} / \underline{\mathrm{W}}_{\mathrm{Het}}
$$

where $\underline{\mathrm{W}}_{\underline{\mathrm{Hom}}}$ is the mean weight for homozygotes and $\underline{\mathrm{W}}_{\text {Het }}$ the mean weight for heterozygotes, with the aim to use homozygote growth rate depression to estimate inbreeding load. The effect of heterozygosity $\underline{\text { versus }}$ homozygosity was tested using a simple ANOVA. For locus Vanna.02 in the EPT population, only one individual appeared heterozygous, but it was the largest of all individuals in the sample. The standardized deviate of this individual was two-tailed tested against the normal distribution. For the COP population, a test of homogeneity of variance between the two samples $t_{1}$ and $t_{2}$ was performed. As the homogeneity was rejected $(\mathrm{F}=0.39 ; \mathrm{df}=29 ; \underline{\mathrm{P}}=0.006)$, data were not pooled, but unilateral $\mathrm{P}$-values for the different tests were combined sample by sample according to Fisher's procedure (Sokal and Rohlf,1996, pp. 794-797). P-values also were combined locus by locus. 
Standardized deviates were plotted on MLH and the relationship between the two parameters was expressed as the product-moment correlation $r$. The significance of $r$ was tested by a t-test (Sokal and Rohlf, 1996, pp. 574-575). To combine the two samples in the COP population, the average r (after ztransformation) was computed after homogeneity among the two correlation coefficients was tested (Sokal and Rohlf, 1996, pp. 581-582).

\section{Results}

\section{$\underline{3.1 \text { Genetic diversity }}$}

Allele frequencies, observed and expected heterozygosities and estimated $F_{\text {is }}$ values are presented in Table 1. Heterogeneity of allele frequencies, as well as that of genotypic frequencies between the two COP samples was always rejected and allowed us to pool the data (results on genotypic frequencies; $\underline{\text { Pstyli.05 }}: \mathrm{Gh}=0.344, \underline{\mathrm{P}}=0.56 ; \underline{\text { Pstyli.19 }}: \mathrm{Gh}=0.014, \underline{\mathrm{P}}=0.9 ; \underline{\text { Pstyli.09 }}: \mathrm{Gh}=0.91, \underline{\mathrm{P}}=0.34$; overall test :

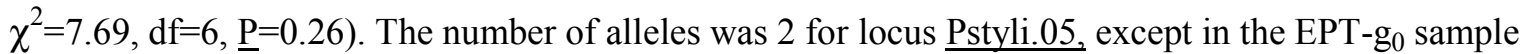
which was monomorphic. It was also 2 for locus Pstyli.19 in each population, and 4 for locus $\underline{\text { Pstyli.09. }}$. The data for locus Vanna.02 in the EPT $-\mathrm{g}_{2}$ population are not presented in Table 1, as only one individual of the 48 analyzed was heterozygous, all other individuals being homozygous (allele frequencies : $400=0.99,398=0.01)$.

As shown by $\mathrm{F}_{\text {is }}$ tests, no significant departure from HWE was observed in the COP population after Bonferroni adjustment, and $\mathrm{F}_{\text {is }}$ for the pooled data was not significant $\left(\mathrm{F}_{\mathrm{is}}=0.03, \mathrm{~ns}\right)$.

On the other hand, the EPT-g $\mathrm{g}_{0}$ population exhibited significant heterozygote deficiency at loci $\underline{\text { Pstyli.05 }}$ $\left(F_{i s}=0.79, \underline{\mathrm{P}}<0.001\right)$ and $\underline{\text { Pstyli.09 }}\left(\mathrm{F}_{\mathrm{is}}=0.24,0.01<\underline{\mathrm{P}}<0.05\right)$, and an overall significant heterozygote deficiency $\left(\mathrm{F}_{\text {is }}=0.37, \mathrm{P}<0.001\right)$. This trend was confirmed in the EPT-g $\mathrm{g}_{2}$ population at the Pstyli.09 locus $\left(F_{i s}=0.4, \underline{\mathrm{P}}<0.01\right)$. Such heterozygote deficiencies could be explained by typing artifacts such as null 
alleles, population substructuring or preferential reproduction between relatives. Other hypotheses such as homogamy, genetic imprinting or selection against heterozygotes, are not expected with DNA microsatellite markers (Hare et al., 1996). As progenitors are randomly chosen and artificially fertilized, there is no reason for the proportion of crosses between relatives to be larger than accounted for by panmixia. According to EPT stock manager, there was no stock mixing at least during the last generation, and thus, the population substructuring hypothesis seems implausible. Segregation of non-amplifying alleles could be a possible explanation of these heterozygotes deficiencies, as it is suspected at least for locus Pstyli.09 (see next section).

\subsection{Suspicion of a PCR artifact at the Pstyli.09 locus}

Two reverse primers were designed for locus Pstyli.09. One of them (sequence :

5'GTAATTATTATCGAACACCCGG-3') failed to amplify allele 210 and was rejected, and the other was published (Vonau et al., 1999). The COP population was analyzed with both reverse primers and the genotypes were deduced from the two data sets. Of the 60 individuals analyzed, scoring of two false homozygotes in sample- $\mathrm{t}_{1}$ and three in sample- $\mathrm{t}_{2}$, were corrected by result of a second amplification with one or the other reverse primer. Segregation of null alleles is, therefore, suspected and could explain in part the heterozygote deficiency observed in sample- $t_{2}$ of the COP population. It exhibited a highly significant deficit $\left(\mathrm{F}_{\mathrm{is}}=0.43, \underline{\mathrm{P}}<0.01\right)$ due to 3 false homozygotes before correction (after correction : $\left.\mathrm{F}_{\text {is }}=0.27,0.01<\underline{\mathrm{P}}<0.05\right)$.

We can calculate the frequency of a null allele explaining $\mathrm{F}_{\mathrm{is}}=0.4$ in the EPT- $\mathrm{g}_{2}$ population $: \mathrm{p}_{\mathrm{o}} \approx 0.2$.

For a sample of 48 individuals, the expected number of null homozygotes is only $48 \mathrm{p}_{\mathrm{o}}^{2} \approx 2$, which is consistent with the result that none were observed. If null alleles effectively segregate in the population, this could also explain the inability to detect heterotic effects at this locus in this population. 
Estimates of allele-frequency variance, $\mathrm{F}_{\mathrm{c}}$, expected $\mathrm{F}_{\mathrm{c}}$ under presumed demographic parameters and the resulting estimate of EPT effective population size, $\mathrm{N}_{\mathrm{e}}$, are presented in Table 2. Over the two generations of drift between EPT- $\mathrm{g}_{0}$ and EPT- $\mathrm{g}_{2}, \mathrm{~N}_{\mathrm{e}}$ was estimated to be $13.6(95 \% \mathrm{CI}=[2,81])$ whereas it was expected to be 100 knowing the presumed management of progenitors in this hatchery. Despite the

6 large variance in the $\mathrm{N}_{\mathrm{e}}$ estimation, due in part to the small number of loci used, this estimate is consistent with an effective population size being smaller than the census size. This is roughly confirmed by the

8 larger variance of allelic frequencies between EPT- $\mathrm{g}_{2}$ and COP than would be expected for 12 generations 9 at $\mathrm{N}_{\mathrm{e}}=37.5$ (harmonic mean of the census population size over the generations). On the other hand,

\subsection{Linkage disequilibrium}

Two-locus correlation coefficients are presented Table 3. No significant linkage disequilibrium was detected in the COP population. A significant linkage disequilibrium was detected between locus $\underline{\text { Pstyli.05 }}$ and $\underline{\text { Pstyli.09 }}(\mathrm{r}=0.223, \underline{\mathrm{P}}<0.01)$ in the EPT-g $\mathrm{g}_{0}$ population and also between $\underline{\text { Pstyli.19 }}$ and $\underline{\text { Pstyli.09 }}$ (significant without Bonferroni adjustment, $\mathrm{r}=0.167,0.01<\underline{\mathrm{P}}<0.05$ ) in the EPT-g 2 population. Expected two-locus correlation coefficients for $\mathrm{N}_{\mathrm{e}}=35$ for the COP population, $\mathrm{N}_{\mathrm{e}}=52$ for the EPT- $\mathrm{g}_{0}$ population and $\mathrm{N}_{\mathrm{e}}=54.5$ for the EPT-g $\mathrm{g}_{2}$ population, are presented Table 3. Linkage disequilibria are 0.42 times the expectation in the COP population and 0.88 times the expectation in the EPT population. Using $\mathrm{N}_{\mathrm{e}}=13.6$, linkage is less than half that expected in the EPT population (when $\mathrm{N}_{\mathrm{e}}=13.6, \mathrm{R}=0.32$ with $\underline{\mathrm{n}}=29$ and $\mathrm{R}=0.3$ with $\underline{n}=48$ ). Because linkage disequilibrium appears lower than that expected, it does not support a smaller effective population size than the census number.

\subsection{Heterozygosity - growth correlation}


The single-locus growth differentials among heterozygotes and homozygotes, and the corresponding tests are presented in Table 4. Combining the two samples, the COP population exhibited significant $\underline{\mathrm{d}}$ at the single test level for two loci, $\underline{\text { Pstyli.05 }}$ and $\underline{\text { P.styli.09, }}$, out of three and the combined probability over the three loci was significant $(\underline{\mathrm{P}}=0.014)$. In the EPT population, only differences in growth among genotypes at locus Pstyli.19 was significant at the single test level, but the combined probability over the three loci was highly significant $(\underline{\mathrm{P}}=0.005)$.

8 Despite a limited sample size, a significant correlation between MLH and the deviate for growth

$9(\mathrm{r}=0.39 ; \underline{\mathrm{P}}=0.034 ;$ Figure 2$)$ was detected in the first sample of the COP population, but not in the second sample ( $\mathrm{r}=0.19 ; \underline{\mathrm{P}}=0.3 ;$ Figure 2$)$, as was suggested in the single locus analysis. Homogeneity between the two correlations was not rejected $\left(\mathrm{t}_{\mathrm{s}}=0.8, \underline{\mathrm{P}}=0.21\right)$, and the average correlation was significant $(\mathrm{r}=0.3$; $\underline{\mathrm{P}}=0.02)$. In the EPT population, a positive correlation was observed, but it was not statistically significant $(\mathrm{r}=0.2 ; \underline{\mathrm{P}}=0.17 ;$ Figure 2$)$.

\section{Discussion}

Although some correlation between heterozygosity at selectively neutral markers and a fitness-related trait is theoretically expected in a finite population (Ohta and Kimura, 1970, 1971; Ohta, 1971, 1973), experimental tests of this prediction mainly have been restricted to allozyme data, for which the neutral status is unclear. Microsatellites showed variability despite population bottlenecks and random genetic drift which arose in Tahitian closed populations. This allowed the use of selectively neutral markers in populations maintained at census population sizes between 20 and 100, the effective population size being likely less, for as long as 22 or 24 generations.

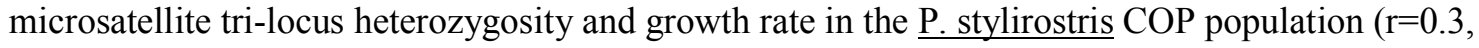


$1 \underline{\mathrm{P}}=0.02)$. The combined test of single locus heterozygote advantage over the three loci was significant as

2 well. In the EPT population, the positive correlation was not significant, but the combined test of single

3 locus heterozygote advantage was significant.

4

5 4.1. Drift analyses : Heterozygosity, variance of allelic frequencies and linkage disequilibrium

6

We have no data on the genetic variability at microsatellite loci in wild populations of $\underline{P \text {. stylirostris, }}$ so we will use here the information already published on other penaeid species (Table 5). High microsatellite variability has been observed in wild penaeid populations, with 4-84 alleles and with heterozygosities exceeding $60 \%$ (usually around $90 \%$ ). Knowing population history, we can calculate the expected heterozygosity for a highly polymorphic microsatellite locus with $\mathrm{H}_{0}=90 \%$ and for a less polymorphic one with $\mathrm{H}_{0}=60 \%$. The expected mean identity-by-descent (IBD) coefficient, $f$, under presumed demographic parameters is :

$$
f=1-\left(1-1 / 2 \mathrm{~N}_{\mathrm{e}}\right)^{\mathrm{t}}
$$

where $\mathrm{N}_{\mathrm{e}}$ is the harmonic mean population size and $\mathrm{t}$ is the number of generations since foundation (Figure 1). Then, the expected heterozygosity is :

$$
\mathrm{H}=\mathrm{H}_{0}(1-f) \text {, }
$$

where $\mathrm{H}_{0}$ is the initial heterozygosity. For the COP population, this produces: $0.44<\mathrm{H}<0.66$, for the EPTgo population : $0.49<\mathrm{H}<0.73$, and for the EPT-g population : $0.48<\mathrm{H}<0.72$, which roughly fit the observed values. However, analysis of heterozygosity is not very powerful to evaluate the effect of genetic drift (Hedgecock and Sly, 1990), and we will further analyze variance of allele frequencies and linkage disequilibrium.

In the EPT population, the use of temporal variance of allelic frequencies led to a smaller estimate of $\mathrm{N}_{\mathrm{e}}\left(\mathrm{N}_{\mathrm{e}}=13.6,95 \% \mathrm{CI}=[2,81]\right)$ than the presumed census population size. This trend was qualitatively reinforced by the bigger variance of allelic frequencies between the EPT- $\mathrm{g}_{2}$ and COP stocks than expected under presumed demographic parameters. The effective population size is expected to be smaller than the 
1 real size in finite populations under directional selection, as demonstrated by Santiago and Caballero

2 (1998), or if variance of reproductive success is large for reasons other than genetic ones (Frankham,

3 1996), as is often the case in marine organisms (Hedgecock, 1994).

$4 \quad$ A trend toward smaller effective population size than expected was not supported by linkage

5 disequilibrium analysis, as linkage disequilibrium was always smaller than expected. An explanation may

6 be provided by heterotic effects. If multi-homozygotes are selected against, the linkage disequilibrium will

7 be reduced, because data on double-heterozygotes are useless for calculating gametic disequilibria on

8 genotypic data.

9 Despite the presumed population size of the EPT population $(\mathrm{N} \approx 100)$ being five times bigger than the

10 COP one $(\mathrm{N} \approx 20)$, the variance of microsatellite allelic frequencies as well as linkage disequilibrium

11 support an equivalent or even smaller effective population size in the EPT- $\mathrm{g}_{2}$ population than in the COP 12 population.

\section{4.2. Heterozygote advantage and inbreeding load}

15

Considering the simplest case, where phenotypic value is linearly correlated with inbreeding :

$$
\underline{\mathrm{W}}=\underline{\mathrm{W}}_{\mathrm{o}}-\beta \underline{f}
$$

in which $\underline{\mathrm{W}}$ is the mean phenotypic value of the population, $\underline{\mathrm{W}}_{\mathrm{o}}$ is the mean phenotypic value in an outbred population, $f$ is the average IBD coefficient, and $\beta$ is the inbreeding load. If the population is partitioned into heterozygotes and homozygotes at the marker locus, this gives :

$$
\underline{\mathrm{W}}_{\text {het }}-\underline{\mathrm{W}}_{\text {hom }}=\beta\left(\underline{f}_{\text {hom }}-\underline{f}_{\text {het }}\right)
$$

where $\underline{\mathrm{W}}_{\text {het }}$ and $\underline{\mathrm{W}}_{\text {hom }}$ are the mean phenotypic values of heterozygotes and homozygotes respectively, and, $f_{\text {het }}$ and $f_{\text {hom }}$ are the mean IBD coefficients of heterozygotes and homozygotes respectively. Markerassociated heterosis is observed when $\underline{f}_{\text {hom }}>f_{\text {het }}$. In other words, when local effects are neglected, associative overdominance is observed when inbreeding depression occurred and when heterozygosity is 
negatively correlated with the IBD coefficient ; note that this correlation depends, among other things, on the variance of IBD coefficient within the population. The magnitude of the associative overdominance will depend on the balance between these two forces.

Ohta (1973) demonstrated that, if the inbreeding load of a chromosome segment with a length of recombination fraction $\mathrm{C}$ is $\beta_{\mathrm{c}}$, then $\delta$, the magnitude of overdominance at a neutral marker located on a different chromosome, is $\delta=\beta_{\mathrm{c}} / 2 \mathrm{~N}_{\mathrm{e}} \mathrm{C}$. This relationship holds irrespective of whether the inbreeding depression is caused by deleterious mutations or by overdominant alleles. The neutral marker is more influenced by selected genes localized on its chromosome, but not by more than a factor of 2 if hs $>0.1$ (Ohta, 1973), where $\mathrm{h}$ is the (over)dominance coefficient and $\mathrm{s}$ is the selective disadvantage of homozygotes at selected genes. As the haploid chromosome number is 46 (Nakaura et al., 1988) in $\underline{\mathrm{P}}$. stylirostris, most of the genome is unlinked to any particular marker. Therefore, we will ignore this factor

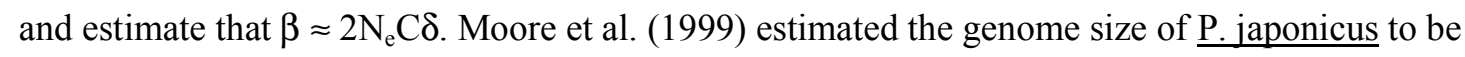

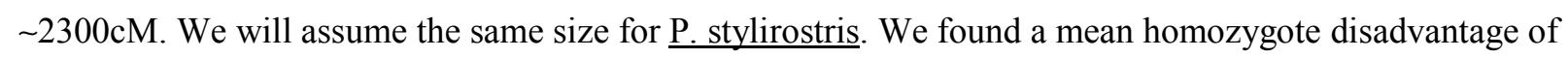
$\delta=0.046$ for growth in the COP population and of $\delta=0.1$ (without locus Vanna.02) or $\delta=0.25$ (with locus

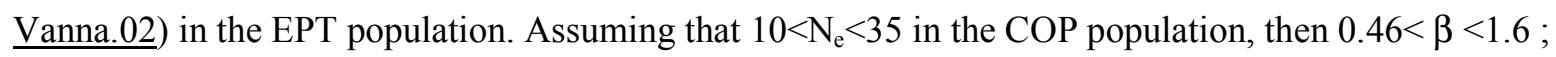
and assuming $13<\mathrm{N}_{\mathrm{e}}<60$ in the EPT population, then $1.3<\beta<6$ (without $\underline{\text { Vanna.02) }}$ ) or $3.25<\beta<15$ (with Vanna.02).

To explain the observed magnitude of associative overdominance, which is actually expected to be quite small even in our small populations (on average, $\underline{f}_{\text {hom }}-\underline{-}_{\text {het }}$ should be small in Eq.7), a high inbreeding depression for growth is needed. The small number of loci used lead to a large variance among estimations, but, even the lower range appears quite high ( $\beta>0.46)$. Falconer and Mackay (1996, p. 248) present some examples of inbreeding depression where the decrease (measured as percentage of noninbred mean) of mean body weight per $10 \%$ increase of IBD coefficient is never higher than $5 \%$, which is the average amount associated with one locus in our case. On the other hand, our results are in accordance with huge genetic loads described in other marine organisms such as bivalves (Bierne et al., 1998). They 
1 have been interpreted as a consequence of the high fecundity of these organisms, which supported such a

2 load, and are a necessary condition for the " general effect " hypothesis of heterozygosity-fitness

3 relationship in natural populations (David et al., 1995 ; David, 1998).

4 The effect of selected genes physically linked to marker loci (local effect) cannot be ruled out.

5 However, it would take an incredibly high number of such genes to explain the finding that such a small

6 number of randomly picked microsatellites would have some in their vicinity.

7

8

9

\section{Conclusion}

To our knowledge, our data are the first indirect demonstration of inbreeding depression in penaeid shrimps. As suspected by presumed demographic histories, and confirmed by genetic analyses, effective population sizes of the two hatchery stocks studied are small. The resulting genetic drift led to homozygosity at microsatellite markers as well as homozygosity at detrimental genes affecting growth rate, the two being correlated among individuals because of variance in individual IBD coefficient. The magnitude of associative overdominance observed in the hatchery propagated stocks of $\underline{\mathrm{P} \text {. stylirostris }}$ appeared large even though our small sample size limits the power of our tests. This suggests a significant residual inbreeding load for growth rate in Tahitian shrimp stocks. Molecular markers are developing very fast in species of aquaculture interest. Checking for marker-associated heterosis could be an approach to rapidly obtain data on the residual inbreeding load in hatchery-propagated stocks where animal pedigrees are unknown.

\section{Acknowledgments}

The authors are very indebted to P. Borsa and P. David for detailed discussions and criticisms while working on this paper, to H. McCombie and F. Volckaert for their comments on the manuscript, and to two anonymous referees for their constructive remarks. The first author also expresses a special thanks to

E. Bernard and L. Philip de Laborie for their help during hemolymph collection. 


\section{References}

AQUACOP, 1979. Penaeid reared broodstock : Closing the life cycle of P.monodon, $\underline{\text { P.stylirostris }}$ and P.vannamei. Proc. World. Maricult. Soc. 10, 445-452.

Bagshaw, J.C., Buckholt, M.A., 1994. Application of DNA marker technologies to shrimp aquaculture. Presented at the World Aquaculture Society Meeting, 11-12 January, New Orleans, LA.

Baldwin, J.D, Bass, A.L., Bowen, B.W., Clark, W.H., 1998. Molecular phylogeny and biogeography of the marine shrimp Penaeus. Mol. Phyl. Evol. 10(3), 399-407.

Bassam, B.J., Caetano-Anolles, G., Gresshof, P.M., 1991. Fast and sensitive silver staining of DNA in polyacrylamide gels. Anal. Biochem. 196, 80-83.

Belkhir, K., Borsa, P., Goudet, J., Chikhi, L., Bonhomme, F., 1996-99. GENETIX, Logiciel sous Windows ${ }^{\mathrm{TM}}$ pour la génétique des populations, version 3.3, Logiciel pour la génétique des populations, Laboratoire Génome et Populations, Université de Montpellier II, http ://www.univ-montp2.fr/genomepop/genetix.htm, Montpellier France.

Bierne, N., Launey, S., Naciri-Graven, Y., Bonhomme, F., 1998. Early effect of inbreeding as revealed by microsatellite analyses on Ostrea edulis larvae. Genetics 148, 1893-1906.

Black, W., Krafsur, E., 1986. Genestat. Theor. Appl. Genet. 70, 471-496.

Britten H.B., 1996. Meta-analyses of the association between multilocus heterozygosity and fitness. Evolution 50, 2158-2164.

Brooker, A.L., Benzie, J.A.H., Blair, D., Versini, J-J. Population structure of the giant tiger prawn, Penaeus monodon, in Australian waters using microsatellite markers. Mar. Biol., in press.

Bush, R.M., Smouse P.E., Ledig F.T., 1987. The fitness consequences of multiple locus heterozygosity : the relationship between heterozygosity and growth rate in pitch pine (Pinus rigida Mill.). Evolution $41,787-798$.

Charlesworth, D., 1991. The apparent selection on neutral marker loci in partially inbreeding populations. Genet. Res. 57, 159-175. 
David, P., 1998. Heterozygosity-fitness correlations: new perspectives on old problems. Heredity 80, 531537.

David, P., Delay, B., Berthou, P., Jarne, P., 1995. Alternative models for allozyme-associated heterosis in the marine bivalve Spisula ovalis. Genetics 139, 1719-1726.

Deng, H.W., Fu, Y.X., 1998. Conditions for positive and negative correlations between fitness and heterozygosity in equilibrium populations. Genetics 148, 1333-1340.

Falconer, D.S., Mckay, T.F.C., 1996. Introduction to quantitative genetics, 4th ed. Longman Group Ltd., Harlow, Essex, England.

Frankham, R., 1996. Relationship of genetic variation to population size in wildlife. Conserv. Biol. 10, 1500-1508.

Gaffney, P. M., 1990. Enzyme heterozygosity, growth rate and viability in Mytilus edulis: Another look. Evolution 44 (1), 204-210.

Garcia, D.K., Faggart, M.A., Rhoades, L., Alcivar-Warren, A.A., 1994. Genetic diversity of cultured Penaeus vannamei shrimp using three molecular genetic techniques. Mol. Mar. Biol. Biotechnol. 3 (5), $270-280$

Garcia, D.K., Dhar, A.K., Alcivar-Warren, A.A., 1996. Molecular analysis of a RAPD marker (B20) reveals presence of two microsatellites and differential mRNA expression in Penaeus vannamei. Mol. Mar. Biol. Biotechnol. 5, 71-83.

Hare, M.P., Karl, S.A., Avise, J.C., 1996. Anonymous nuclear DNA markers in the American oyster and their implications for the heterozygote deficiency phenomenon in marine bivalves. Mol. Biol. Evol. 13, $334-345$

Hedgecock, D., 1994. Does variance in reproductive success limit effective population sizes of marine organisms? In: Beaumont, A.R. (Ed.). Genetics and evolution of aquatic organisms, Chapman \& Hall, London, pp 122-134.

Hedgecock, D., Nelson, K., Tracey, M.L., 1982. Genetics. In : Abele, L.G. (Ed.). The biology of crustacea, vol.2, Academic Press, New York, pp. 283-403. 
1 Hedgecock, D., Sly, F., 1990. Genetic drift and effective population sizes of hatchery-propagated stocks of the Pacific oyster, Crassostrea gigas. Aquaculture 88, 21-38.

Latter, B.D.H., Mulley, J.C., Reid, D., Pascoe, L., 1995. Reduced genetic load revealed by slow inbreeding in Drosophila melanogaster. Genetics 139, 287-297.

Laubier A., Pasteur, N., Moriyasu M., 1984. Estimation du polymorphisme enzymatique d'une population de Penaeus japonicus maintenue en élevage depuis quatre générations. Oceanologia Acta 7(4), 451456.

Leary, R.F., Allendorf, F.W., Knudsen K.L., 1984. Superior developmental stability of heterozygotes at enzyme loci in salmonid fishes. Am. Nat. 124, 540-551.

Mitton, J. B., 1993. Theory and data pertinent to the relationship between heterozygosity and fitness. In: Thornhill, N.W. (Ed.). The natural history of inbreeding and outbreeding - theoritical and empirical perspectives, University of Chicago Press, Chicago, pp. 17-41.

Mitton, J.B., Grant, M.C., 1984. Associations among protein heterozygosity, growth rate, and developmental homeostasis. Ann. Rev. Ecol. Syst. 15, 479-499.

Moore, S.S., Whan, V., Davis, G.P., Byrne, K., Hetzel, D.J.S., Preston, N., 1999. The development and application of genetic markers for Kuruma prawns Penaeus japonicus. Aquaculture 173, 19-32.

Mulley, J.C., Latter, B.D.H., 1980. Genetic variation and evolutionary relationships within a group of thirteen species of Penaeid prawns. Evolution 34 (5), 904-916.

Nakaura, H.K., Machii, A., Wada, K.T., Awaji M., Townsley, S.J., 1988. A check list of decapod chromosomes (Crustacea). Bull. Natl. Res. Aquac. 13, 1-9.

Nei, M., 1978. Estimation of average heterozygosity and genetic distance from a smal number of individuals. Genetics 89, 583-590.

Nei, M. and Tajima, F., 1981. Genetic drift and estimation of effective population size. Genetics 98, 625640.

Ohta, T., 1971. Associative overdominance caused by linked detrimental mutations. Genet. Res. 18, 277286. 
Ohta, T., 1973. Effect of linkage on behavior of mutant genes in finite populations. Theor. Pop. Biol. 4, $145-162$.

Ohta, T., Cockerham, C.C., 1974. Detrimental genes with partial selfing and effects on a neutral locus. Genet. Res. 23, 191-200.

Ohta, T., Kimura, M., 1970. Development of associative overdominance through linkage disequilibrium in finite populations. Genet. Res. 16, 165-177.

Ohta, T., Kimura, M., 1971. Behavior of neutral mutants influenced by associated overdominant loci in finite populations. Genetics 69, 247-260.

Palumbi, S.R., Benzie, J., 1991. Large mitochondrial DNA differences between morphologically similar Penaeid shrimp. Mol. Mar. Biol. Biotech. 1, 27-34.

Pogson, G. H., Zouros, E., 1994. Allozyme and RFLP heterozygosities as correlates of growth rate in the scallop Placopecten magellanicus: A test of the associative overdominance hypothesis. Genetics 137 , $221-231$.

Pogson, G.H., Fevolden, S.E., 1998. DNA heterozygosity and growth rate in the Atlantic cod Gadus morhua (L). Evolution 52(3), 915-920.

Pullin, R.S.V., Wiliams, M.J., Preston, N., 1998. Domestication of crustaceans. Asian Fisheries Science. (in press).

Santiago, E., Caballero, A., 1998. Effective size and polymorphism of linked neutral loci in populations under directional selection. Genetics 149, 2105-2117.

Sbordoni, V., La Rosa, G., Mattoccia, M., Cobolli-Sbordoni, M., De Matthaeis, E., 1987. Genetic changes in seven generations of hatchery stocks of the Kuruma prawn, Penaeus japonicus (Crustacea Decapoda). In: Tiews, K. (Ed.). Selection, hybridization and genetic engineering in aquaculture, Heenemann Verlag, Berlin, West Germany, pp.143-155.

Singer-Sam, J., Tanguay, R. L., Riggs, A. D., 1989. Use of chelex to improve the PCR signal from a small number of cells. Amplifications : a forum for PCR users. Issue 3 (September) : 11. 
1 Smouse, P.E., 1986. The fitness consequences of multiple-locus heterozygosity under the multiplicative overdominance and inbreeding depression models. Evolution 40, 946-957.

Sokal, R.R., Rohlf, F.J., 1996. Biometry, 3rd ed. Freeman \& Co., New York.

Strobeck, C., 1979. Partial selfing and linkage: the effect of a heterotic locus on a neutral locus. Genetics $92,305-315$.

Sunden, S.L.F., Davis S.K., 1991. Evaluation of genetic variation in a domestic population of $\underline{\text { Penaeus }}$ vannamei (Boone) : a comparison with three natural populations. Aquaculture 97, 131-142.

Tassanakajon, A., Tiptawonnukul, A., Supungul, P., Rimphanitchayakit, V., Cook, D., Jarayabhand, P., Klinbunga, S., Boonsaeng, V., 1998. Isolation and characterization of microsatellite markers in the black tiger prawn Penaeus monodon. Mol. Mar. Biol. Biotech. 7, 55-61.

Turelli, M., Ginzburg L.R., 1983. Should individual fitness increase with heterozygosity? Genetics 104, 191-209.

Vonau, V., Ohresser, M., Bierne, N., Delsert, C., Beuzart, I., Bedier, E., Bonhomme, F. Three polymorphic microsatellites in the shrimp Penaeus stylirostris. Animal Genetics 30, 234-235.

Waples, R.S., 1989. A generalized approach for estimating effective population size from temporal changes in allele frequency. Genetics 121, 379-391.

Weir, B.S., 1979. Inferences about linkage disequilibrium. Biometrics 35, 235-254.

Weir, B.S., Hill, W.G., 1980. Effect of mating structure on variation in linkage disequilibrium. Genetics $95,477-488$.

Weir, B.S., Cockerham, C.C., 1984. Estimating F-statistics for the analysis of population structure. Evolution 38, 1358-1370.

Weppe M., Bonami J.R., Lightner D.V., Aquacop, 1992. Demonstracion de las altas cualidades de la cepa

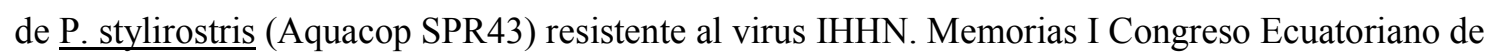
Acuicultura, CENAIM, Guyaquil, Ecuador, pp. 229-232.

Wolfus, G.M., Garcia, D.K. and Alcivar-Warren, A., 1997. Application of the microsatellite technique for analysing genetic diversity in shrimp breeding programs. Aquaculture 152, 35-47. 
1 Wright, S., 1951. The genetical structure of populations. Annals of Eugenics 15, 323-354.

2 Zouros E., 1987. On the relation between heterozygosity and heterosis : an evaluation of the evidence

3 from marine mollusks. Isozymes 15, 255-270.

4 Zouros, E., 1993. Associative overdominance: evaluating the effects of inbreeding and linkage

5 desequilibrium. Genetica 89, 35-46.

6 Zouros, E., Singh, S.M., Miles, H.E., 1980. Growth rate in oysters: an overdominant phenotype and his $7 \quad$ possible explanations. Evolution 42, 1332-1334.

8 Zouros, E., Pogson, G.H., 1994. Heterozygosity, heterosis and adaptation. In: Beaumont, A.R. (Ed.).

9 Genetics and evolution of aquatic organisms, Chapman \& Hall, London, pp. 135-146 


\section{TABLE 1}

2

3 Allele frequencies, observed and expected heterozygosity, and $F_{\text {is }}$ at three microsatellite loci in two

4 temporal samples of the same generation of the P. stylirostris COP population $\left(\mathrm{t}_{1}:\right.$ mean weight $=26.8 \mathrm{~g}$

$5 \quad, \mathrm{t}_{2}$ : mean weight $\left.=43.1 \mathrm{~g}\right)$ and in the two generation sample of the EPT population (EPT- $\mathrm{g}_{2}$ is two

6 generations younger than EPT- $\left.\mathrm{g}_{0}\right)$. Permutation approach tests were computed with 5000 permutations

7 with the Genetix software (Belkir et al., 1996-99).

8

\begin{tabular}{|c|c|c|c|c|c|}
\hline $\begin{array}{l}\text { Population } \\
\text { Sample size }\end{array}$ & $\begin{array}{c}\mathrm{COP}-\mathrm{t}_{1} \\
30\end{array}$ & $\begin{array}{c}\mathrm{COP}-\mathrm{t}_{2} \\
30\end{array}$ & $\begin{array}{l}\text { COP }-\mathrm{t}_{1}+\mathrm{t}_{2} \\
\text { Combined }\end{array}$ & $\begin{array}{c}\mathrm{EPT}-\mathrm{g}_{0} \\
29\end{array}$ & $\begin{array}{c}\text { EPT }-g_{2} \\
48\end{array}$ \\
\hline \multicolumn{6}{|l|}{ Locus Pstyli.05 } \\
\hline 180 & 0.68 & 0.75 & 0.72 & 0.8 & 1 \\
\hline 210 & 0.32 & 0.25 & 0.28 & 0.2 & 0 \\
\hline $\mathrm{H}_{\exp }$ & 0.44 & 0.38 & 0.41 & 0.33 & \\
\hline $\mathrm{H}_{\text {obs }}$ & 0.57 & 0.43 & 0.5 & 0.07 & - \\
\hline $\mathrm{F}_{\text {is }}$ & $-0.29^{\mathrm{ns}}$ & $-0.14^{\mathrm{ns}}$ & $-0.22^{\mathrm{ns}}$ & $0.79^{* * * a}$ & \\
\hline
\end{tabular}

Locus Pstyli.19

\begin{tabular}{llllll}
\hline 210 & 0.83 & 0.77 & 0.8 & 0.55 & 0.44 \\
214 & 0.17 & 0.23 & 0.2 & 0.45 & 0.56 \\
$\mathrm{H}_{\text {exp }}$ & 0.28 & 0.36 & 0.32 & 0.5 & 0.5 \\
$\mathrm{H}_{\text {obs }}$ & 0.27 & 0.33 & 0.3 & 0.37 & 0.46 \\
$\mathrm{~F}_{\text {is }}$ & $0.06^{\mathrm{ns}}$ & $0.08^{\mathrm{ns}}$ & $0.07^{\mathrm{ns}}$ & $0.28^{\mathrm{ns}}$ & $0.08^{\mathrm{ns}}$
\end{tabular}

\section{Locus Pstyli.09}

\begin{tabular}{|c|c|c|c|c|c|}
\hline 210 & 0 & 0.02 & 0.01 & 0.11 & 0.19 \\
\hline 218 & 0.27 & 0.25 & 0.26 & 0.48 & 0.4 \\
\hline 220 & 0.28 & 0.35 & 0.315 & 0.24 & 0.24 \\
\hline 222 & 0.45 & 0.38 & 0.415 & 0.17 & 0.17 \\
\hline$H_{\text {exp }}$ & 0.66 & 0.68 & 0.66 & 0.68 & 0.72 \\
\hline $\mathrm{H}_{\mathrm{obs}}$ & 0.6 & 0.5 & 0.55 & 0.52 & 0.17 \\
\hline $\mathrm{F}_{\text {is }}$ & $0.09^{\mathrm{ns}}$ & $0.27^{*}$ & $0.17^{\mathrm{ns}}$ & $0.24^{*}$ & $0.4^{* * * a}$ \\
\hline ( $\Sigma$ locus $)$ & $-0.04^{\mathrm{ns}}$ & $0.11^{\mathrm{ns}}$ & $0.03^{\mathrm{ns}}$ & $0.37^{* * * a}$ & $0.27^{* * * a}$ \\
\hline
\end{tabular}

9 ns, not significant; * $: \underline{\mathrm{P}}<0.05, * *: \underline{\mathrm{P}}<0.01, * * *: \underline{\mathrm{P}}<0.001$,

10 a significant after Bonferroni adjustment. 
1 TABLE 2

2

3 Variance of allelic frequencies, $F_{c}$, between pairs of populations, expected $F_{c}$ from the

4 presumed demographic histories and estimation of EPT effective population size, $\mathrm{N}_{\mathrm{e}}$.

5

\begin{tabular}{llll}
\hline & ${\text { EPT }-g_{0}-\text { EPT }^{-g_{2}}}$ & COP - EPT-g $_{0}$ & COP - EPT-g $g_{2}$ \\
\hline$\underline{\text { Pstyli.05 }}$ & 0.4 & 0.035 & 0.56 \\
$\underline{\text { Pstyli.19 }}$ & 0.05 & 0.266 & 0.484 \\
$\underline{\text { Pstyli.09 }}$ & 0.017 & 0.174 & 0.203 \\
& & & \\
$\mathrm{~F}_{\mathrm{c}}(95 \% \mathrm{CI})$ & $0.1[0.04,0.61]$ & $0.165[0.06,0.96]$ & $0.33[0.12,1.9]$ \\
Expected F & $0.038^{\mathrm{a}}$ & $0.175^{\mathrm{b}}$ & $0.178^{\mathrm{c}}$ \\
$\mathrm{N}_{\mathrm{e}}(95 \% \mathrm{CI})$ & $13.6[2,81]$ & - & - \\
& & & \\
\hline
\end{tabular}

$6{ }^{\mathrm{a}}$ expected $\mathrm{F}_{\mathrm{c}}$ with $\mathrm{N}_{\mathrm{e}}=100$ over two generations

$7 \quad{ }^{\mathrm{b}}$ expected $\mathrm{F}_{\mathrm{c}}$ with $\mathrm{N}_{\mathrm{e}}=33.3$ over 10 generations

$8 \quad{ }^{c}$ expected $F_{c}$ with $\mathrm{N}_{\mathrm{e}}=37.5$ over 12 generations 
1 TABLE 3

2

3 Correlations of gene frequencies. Correlation coefficients, R, and permutation

4 approach tests were computed with the Genetix software (Belkir et al., 1996-

5 99).

6

\begin{tabular}{clll}
\hline Pair & COP $-\mathrm{t}_{1}+\mathrm{t}_{2}$ & EPT - $g_{0}$ & EPT - $g_{2}$ \\
\hline$\underline{\text { Pstyli.05 - Pstyli.19 }}$ & 0.073 & 0.162 & - \\
$\underline{\text { Pstyli.05 - Pstyli.09 }}$ & 0.096 & $0.223^{* *}$ & - \\
$\underline{\text { Pstyli.19 - Pstyli.09 }}$ & 0.097 & 0.111 & $0.167^{*}$ \\
& & & \\
\hline Mean & 0.088 & 0.165 & 0.167
\end{tabular}

\begin{tabular}{llll} 
Expected R $\quad(0.21)^{\mathrm{a}} \quad(0.23)^{\mathrm{b}} \quad(0.20)^{\mathrm{c}}$ \\
\hline
\end{tabular}

$7 *: \underline{\mathrm{P}}<0.05, * *: \underline{\mathrm{P}}<0.01, * * *: \underline{\mathrm{P}}<0.001$.

$8 \quad{ }^{a}$ expected $\mathrm{R}$ with $\mathrm{N}_{\mathrm{e}}=35$

$9 \quad{ }^{b}$ expected R with $\mathrm{N}_{\mathrm{e}}=52$

$10{ }^{\mathrm{c}}$ expected $\mathrm{R}$ with $\mathrm{N}_{\mathrm{e}}=54.5$ 
2

3 Growth comparison between single-locus heterozygotes and homozygotes. $\underline{\mathrm{d}}$ is the mean

4 standardized growth in heterozygotes minus the mean standardized growth in homozygotes. $\delta$ is

5 the homozygote depression for growth measured as percentage of heterozygotes mean weight.

6

\begin{tabular}{|c|c|c|c|c|}
\hline & $\mathrm{COP}-\mathrm{t}_{1}$ & $\mathrm{COP}-\mathrm{t}_{2}$ & $\mathrm{COP}-\mathrm{t}_{1}+\mathrm{t}_{2}$ & EPT $-g_{2}$ \\
\hline \multirow[t]{2}{*}{$\underline{\text { Pstyli.05 }}$} & $\mathrm{d}=0.52^{\mathrm{ns}}$ & $\mathrm{d}=0.60^{\mathrm{ns}}$ & $\mathrm{d}=0.56^{*}$ & - \\
\hline & $\delta=8 \pm 7 \%$ & $\delta=6 \pm 5 \%$ & $(\delta=7.5 \%)$ & \\
\hline \multirow[t]{2}{*}{ Pstyli.19 } & $\mathrm{d}=0.16^{\mathrm{ns}}$ & $\mathrm{d}=-0.04^{\mathrm{ns}}$ & $\mathrm{d}=0.06^{\mathrm{ns}}$ & $d=0.65^{*}$ \\
\hline & $\delta=2 \pm 6.5 \%$ & $\delta=-0.6 \pm 5 \%$ & $(\delta=0.7 \%)$ & $\delta=29 \pm 16 \%$ \\
\hline \multirow[t]{2}{*}{ Pstyli.09 } & $\mathrm{d}=0.86^{*}$ & $\mathrm{~d}=0.05^{\mathrm{ns}}$ & $\mathrm{d}=0.46^{*}$ & $\mathrm{~d}=-0.22^{\mathrm{ns}}$ \\
\hline & $\delta=11 \pm 6 \%$ & $\delta=0.7 \pm 5 \%$ & $(\delta=5.8 \%)$ & $\delta=-9 \pm 21 \%$ \\
\hline \multirow[t]{4}{*}{$\underline{\text { Vanna.02 }}$} & - & - & - & $\mathrm{d}=1.74^{\mathrm{ns}}$ \\
\hline & & & & $(\delta=56 \%)$ \\
\hline & $\mathrm{d}=0.51^{*}$ & $\mathrm{~d}=0.2^{\mathrm{ns}}$ & $\mathrm{d}=0.36^{{ }^{*} \mathrm{a}}$ & $\mathrm{d}=0.72^{* a}$ \\
\hline & $(\delta=7 \%)$ & $(\delta=2 \%)$ & $(\delta=4.6 \%)$ & $(\delta=25 \%)$ \\
\hline
\end{tabular}

7 ns, not significant; * $: \underline{\mathrm{P}}<0.05,{ }^{* *}: \underline{\mathrm{P}}<0.01,{ }^{* * *}: \underline{\mathrm{P}}<0.001$,

$8 \quad$ a significant after Bonferroni adjustment. 
1 TABLE 5

2

3 Microsatellite characteristics in wild penaeid shrimp populations.

4

\begin{tabular}{lcccl}
\hline Species & No of loci & No of alleles & Heterozygosity & References \\
\hline$\underline{\text { Penaeus vannamei }}$ & 1 & 22 & 0.95 & Wolfus et al., 1997 \\
$\underline{\text { Penaeus monodon }}$ & 2 & $14-28$ & $0.83-0.95$ & Tassanakajon et al., 1998 \\
$\underline{\text { Penaeus monodon }}$ & 3 & $35-84$ & $0.92-0.96$ & Brooker et al., in press \\
$\underline{\text { Penaeus japonicus }}$ & 12 & $4-24$ & $0.6-0.93$ & Moore et al., 1999 \\
\hline
\end{tabular}

5 
$1 \quad$ Figure legend

2

3 Figure 1 : Presumed demographic and inbreeding histories of the COP and EPT hatchery-propagated $\underline{\mathrm{P}}$.

$4 \quad$ stylirostris stocks. $\Delta \mathrm{F}$ is the expected inbreeding increment per generation, $\mathrm{N}$ is the population size, and $f$

5 is the expected mean inbreeding coefficient of the stock when sampled. Estimated $\mathrm{F}_{\mathrm{st}}$ values between pairs

6 of populations and their significance level, are specified : ${ }^{*}: \underline{\mathrm{P}}<0.05, * *: \underline{\mathrm{P}}<0.01, * * *: \underline{\mathrm{P}}<0.001$.

7

8 Figure 2 : $\underline{\mathrm{P} . \text { stylirostris }}$ standardized deviates of weight $(95 \%$ C.I $)$, as a function of microsatellite

9 multilocus heterozygosity (MLH, number of heterozygous loci per individual), for the two samples of the

10 COP population and for the EPT-g $\mathrm{g}_{2}$ population. Linear tendency curves are plotted, and r values are

11 product-moment correlations. Number of individuals per MLH class are indicated in brackets. 
1 Figure 1

2

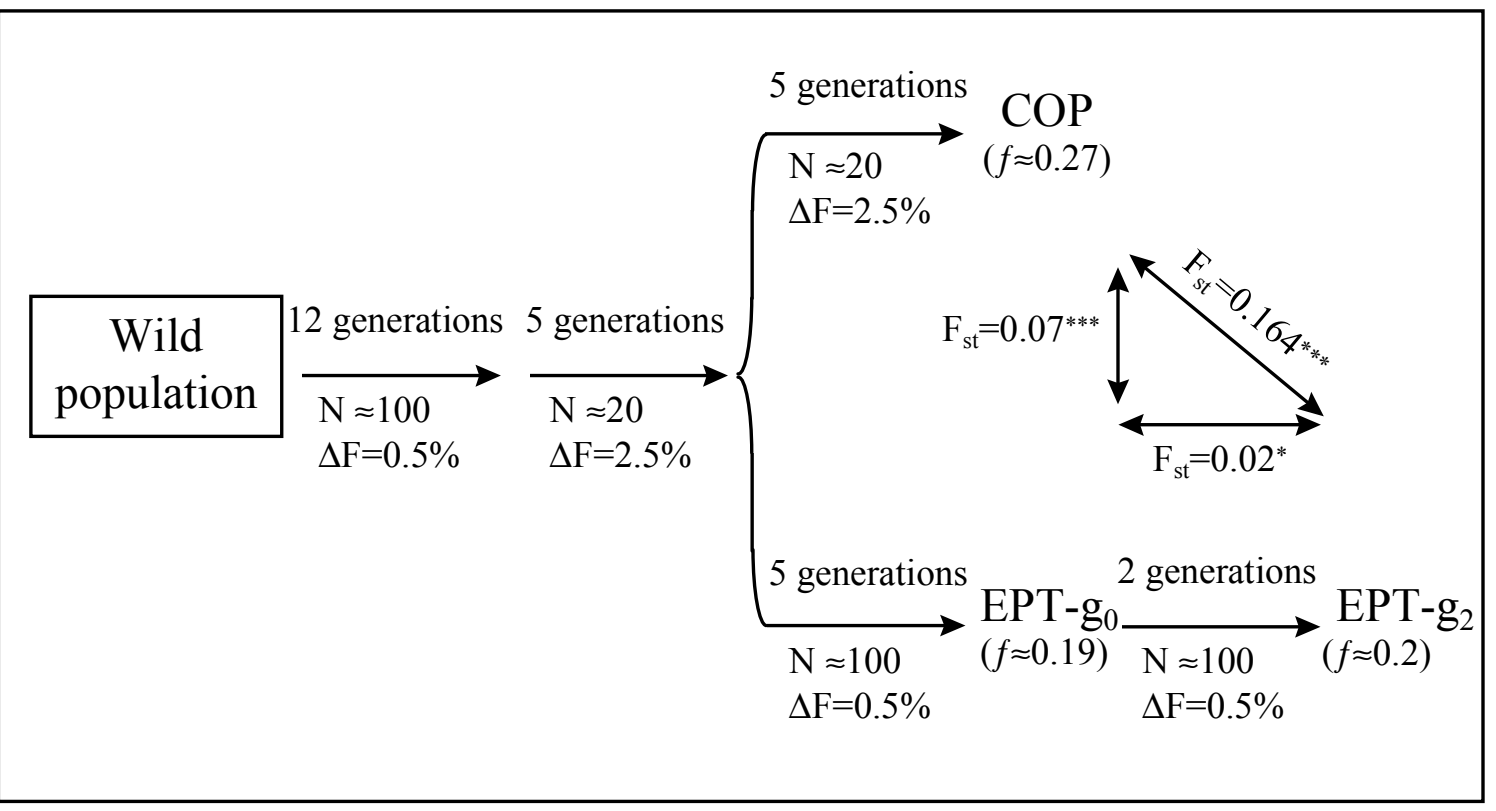

4 
1 Figure 2

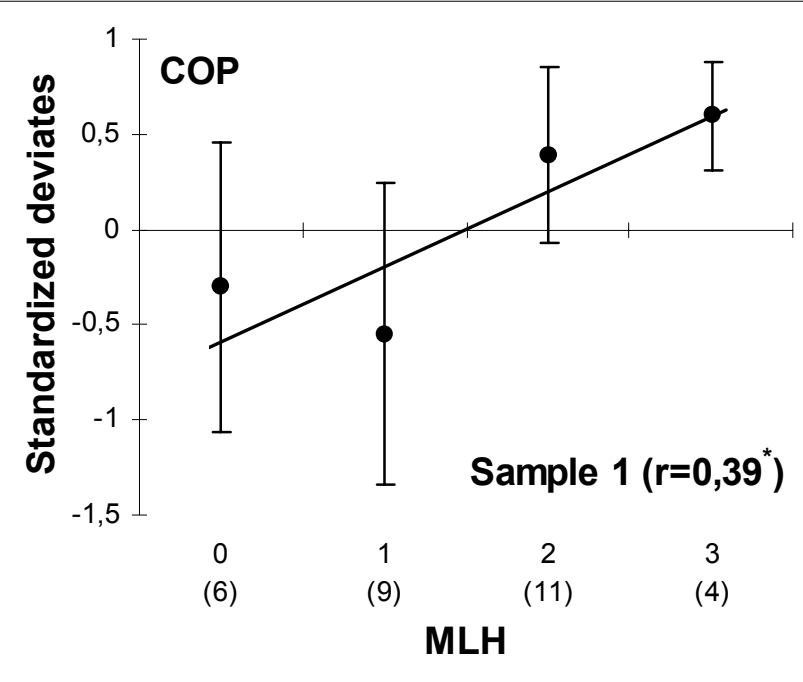

2

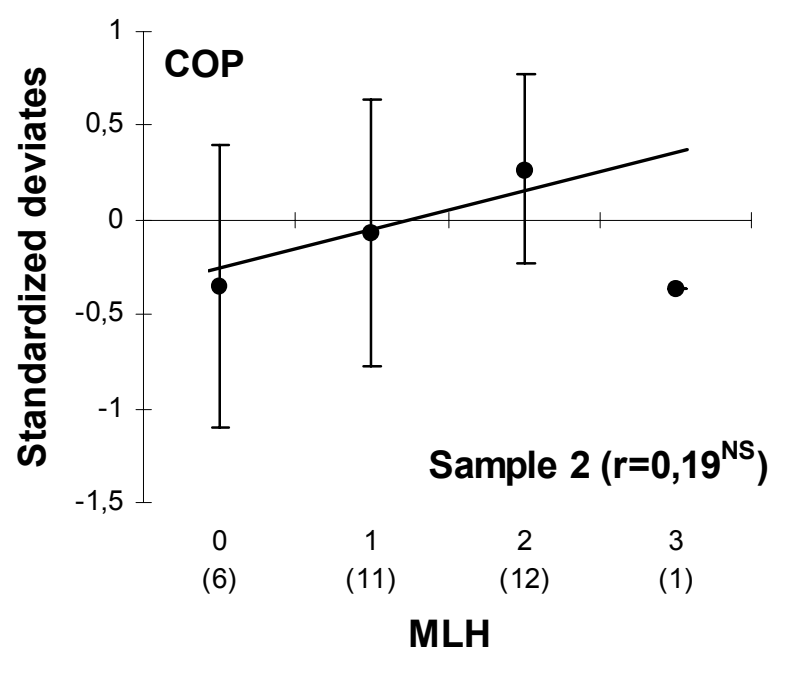

3 
1

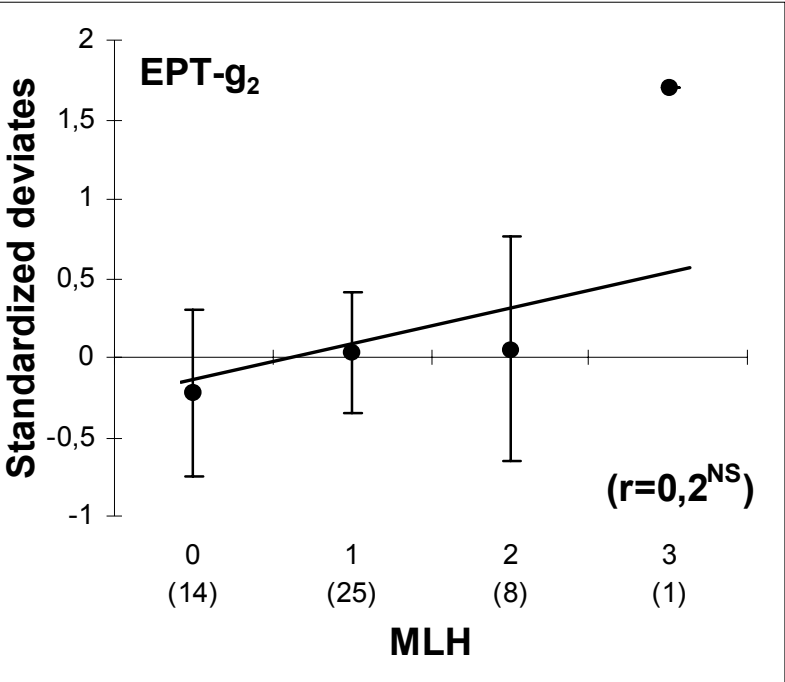

